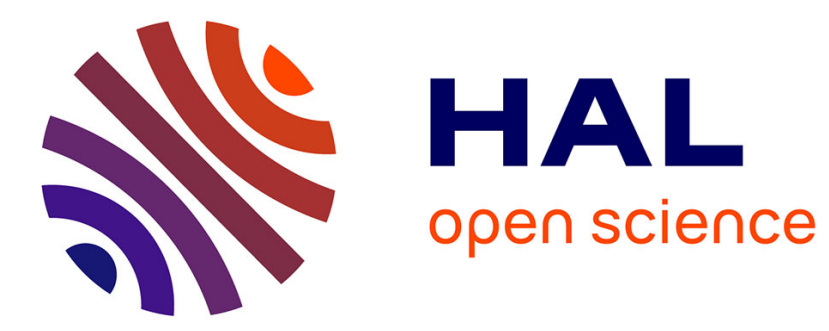

\title{
Towards a nanorisk appraisal framework
}

Rye Senjen, Steffen Foss Hansen

\section{To cite this version:}

Rye Senjen, Steffen Foss Hansen. Towards a nanorisk appraisal framework. 2011. hal-00598256v2

\section{HAL Id: hal-00598256 \\ https://hal.science/hal-00598256v2}

Preprint submitted on 7 Jun 2011

HAL is a multi-disciplinary open access archive for the deposit and dissemination of scientific research documents, whether they are published or not. The documents may come from teaching and research institutions in France or abroad, or from public or private research centers.
L'archive ouverte pluridisciplinaire HAL, est destinée au dépôt et à la diffusion de documents scientifiques de niveau recherche, publiés ou non, émanant des établissements d'enseignement et de recherche français ou étrangers, des laboratoires publics ou privés. 


\title{
Towards a nanorisk appraisal framework
}

Rye Senjen, School of Political and Social Inquiry, Sociology, Monash University, Melbourne, Australia, Tel + 6139481 0145, rye.senjen@monash.edu

Steffen Foss Hansen, DTU Environment, Technical University of Denmark, DTU-Building 113, Kgs. Lyngby, DK-2800

\begin{abstract}
The paper discusses in the context of nanotechnology whether current concepts of chemical risk assessment can be used to assess nanorisk. Nanorisk can be defined from the narrow (eco) toxicological perspective to the broader sense to include societal/cultural impacts or even to the fundamental philosophical level i.e. questioning societies need for the technology. We outline here the limitations of chemical risk assessment and other recent proposed risk governance paradigms in relation to nanotechnology and nanomaterials, including, its inability to include societal risks (ownership, privacy, security, nanodivide ${ }^{1}$, convergence of nano-, bio-, etc.) and metaphysical risk (including the lay persons perspective on the risks of nanotechnology). Finally, we outline the fundamental principles and criteria that an alternative comprehensive framework should be based on.
\end{abstract}

Keywords: nanotechnology, nanomaterials, risk appraisal framework, types of knowledge, types of risk, metaphysical risk

\begin{abstract}
Résumé
Ce papier est une discussion sur la viabilité des concepts habituellement utilisés dans le cadre du risque chimique, lorsqu'il s'agit d'évaluer les «nanorisques ». Le nanorisque peut être défini suivant des perspectives variées de celle, restreinte, du risque eco-toxicologique à celle plus large de l'impact sociétal ou culturel, voire même sous l'angle plus philosophique du questionnement de la pertinence du besoin en technologies de la société. Nous résumerons les limitations des évaluations du type "risque chimique" et de celles d'autres schémas de gouvernance récemment proposés en relation avec les nanotechnologies ou les nanomatériaux, en particulier leur incapacité à prendre en compte le risque «sociétal » (propriété de technologies, vie privée, sécurité, « nanodivide ${ }^{2}$, convergence nano-bio, etc ..) et le risque « métaphysique » (notamment l'avis du profane sur ces risques). Finalement, nous définirons les principes fondamentaux et les critères sur lesquels un cadre prenant en compte l'ensemble de ces questions devrait être fondé.
\end{abstract}

Mots clés: nanotechnologie, nanomatériaux, cadre d'évaluation des risques, type de connaissance, type de risque, risque métaphysique.

\section{Introduction}

Nanotechnology as a science has come a long way since Feynman in his now famous lecture "There is plenty of room at the bottom" in 1959, first explored some of the distinguishing concepts that would later become known as nanotechnology. In this lecture he described a process that uses a set of precise tools that would allow the manipulation of individual atoms and molecules [1]. The term to describe this process, nanotechnology, was later in 1974, coined by Norio Taniguchi in the context of semi-conductor processes. He defined nanotechnology as the processing of separation, consolidation, and deformation of materials by one atom or by one

\footnotetext{
${ }^{1}$ Gap between between those who possess nanotechnologies and those don't

${ }^{2}$ Fossé entre ceux qui disposent de ces technologies et ceux qui n'en disposent pas
} 
molecule [2]. Initially, nanotechnology was driven by basic scientific research and the accompanying individual scientific breakthroughs including the discovery of a number of nanomaterials such as fullerenes, quantum dots and carbon nanotubes, along with the invention of the scanning tunneling microscopy and atomic force microscopy ([3], [4], [5]).

Today nanotechnology is an established area of cross disciplinary research, as well as a billion dollar industry. How much nanotechnology contributes to the global economy is a controversial issue in itself. A recent report by BCC research claims that total global sales revenues for nanotechnology were US $\$ 11.6$ billion in 2009 , and are expected to reach more than US $\$ 26$ billion by 2015 [6]. This is of course a substantial contribution, but much lower than the earlier estimate by the US National Science Foundation of $\$ 1$ trillion by 2015 . Larger revenue estimates of US $\$ 1.5$ trillion to US $\$ 2.9$ trillion by 2014 rely on the concept of market being defined more widely, to include the value of nano-enabled products [7], rather than 'just' looking at nanomaterials, nanodevices and nanotools.

Much of nanotechnology literature emphasizes nanotechnology as the engines of the next industrial revolution and extols the incredible benefits that nanotechnological innovation is predicted to bring [8]. While research and policy decisions emphasizing risk (e.g. see [9], [10]) are of course not absent, it is relatively rare that the risk issues are discussed comprehensively under one framework. A particular framework might address one or the other aspect of nanotechnology associated risk, but none of them include risk issues ranging from the narrow (eco) toxicological concerns to the broad societal/cultural impacts to the fundamental issues i.e. questioning societies need for the technology. The purpose of this dominant narrative of linking the idea of progress with technological innovation is to privilege presumed benefits over as yet unknown risks. It is therefore rare for risk issues to be discussed together with innovation on an equal basis, despite the fact that these influence each other greatly [11].

Non-governmental actors (unions, environmental NGOs) and commentators view nanotechnology from a distant existential risk ([12] to a concern regarding the potentially toxic impact of nanomaterials on humans and the environment ([9], [13], [14], [15]).

SwissRe [Swiss Re 82] raised the alarm bells, when it concluded that because of certain physical similarities between asbestos and certain carbon nanotubes the latter may have the potential to cause similar harm. Asbestos causes, usually after an extended incubation period, Mesothelioma, a cancer that affects the lining of internal organs, especially the lung and the stomach. Preliminary studies by Poland and co-workers [83] indeed found that long and entangled multiwalled carbon nanotubes introduced into the abdominal cavity of mice produced asbestoslike pathogenicity. Interestingly, short and entangled multiwalled carbon nanotubes did not cause these effects. Donaldson et al. [84] hypothesized that other high aspect ratio nanoparticles (HARN) may also cause inflammation of the lung or even induce mesothelioma.

In contrast many nanotechnology scientists, scientists and governments seem to assume that nanotechnology and nanomaterials are relatively safe and that concerns about risks are overblown [16]. This apparent asymmetry between the intended benefits and the unforeseen harm nanotechnologies may harbour, results in presumed benefits appearing more immediate, knowable and predictable, especially to those close to the 'production' of such technologies. The possible and as yet hidden hazards tend to recede and become more unlikely as the effects of benefits are focused upon. [17].

A key question in the above context then is who is responsible for the risks, who bares or will bare the costs and who will asses and manage the risks and which principles and criteria will they use to guide the assessment and management of known and unknown risks.

Numerous commentators (e.g. [18], [19]) have drawn an analogy between genetically-modifiedorganisms (GMOs) and nanotechnology and how the backlash against the former should inform risk communication/management on the latter about the need to address the social and ethical 
dimensions of nanotechnology with the aim to ensure nanotechnologies 'acceptance' within the wider community. Increasingly governments have also realised that public trust and acceptance of new technologies is a necessary, but not easily achievable component of technology adoption in the $21^{\text {st }}$ Century [20]. A key issue in drawing this analogy is that it leads to the belief that the main role of public engagement is to make technological innovations acceptable to the public and avoid resistance to them, rather than drawing the public into an active role in determining the direction of technological innovations. In the latter case, the public would through various democratic processes be involved in setting the objectives and constraints of (nano)technology research and how they can be pursued. It would then be the project of science and industry to turn these objectives, taking into account societal constraints, into economically viable technologies [21].

In this paper, we will first discuss the current understanding of what risks are and especially nanorisk and how some commentators envision that chemical risk assessment can be used to assess nanorisk. We then outline the limitations of chemical risk assessment and other recent proposed risk governance paradigms in relation to nanotechnology and nanomaterials, for instance, its inability to include societal risks (ownership, privacy, security, nanodivide i.e in the sense of Global South versus Global North convergence of nano-, bio-, etc.) and metaphysical risk (including the lay persons perspective on the risks of nanotechnology). Finally, we outline the fundamental principles and criteria that an alternative comprehensive framework should be based on.

\section{Current understanding of what risks are and especially nanorisk}

Renn [22] defines risk broadly as "the likelihood that an undesirable state of reality (adverse effects) may occur as a result of natural events or human activities". This definition implies, at its most general level that there are outcomes (positive or negative), the likelihood of these outcomes occurring i.e. uncertainty and a specific context in which the outcomes may occur. Technically then, risk is the probability that an undesirable outcome (hazard) multiplied by the magnitude of the impact, will occur [23].

Conventionally and in the context of many risk assessment paradigms (technical, mathematical and model-based), risk is viewed as physical risk - i.e. physical harm to humans, cultural artifacts or ecosystems. Risk events are averaged out over time and space and probabilities are estimated to determine the likelihood of an event occurring [22]. Risk itself is then defined as hazard multiplied by exposure.

Key risks of nanotechnology have been defined by various commentators under the main headings of:

- Human health and environment i.e. physical harm to human health or impact environmental organisms, ecosystem structure and functioning.

- Ownership of technology and accountability i.e. cooperate ownership and development of technologies that may be of great benefit to society without seemingly being held accountable should these turn out to entail risks.

- Privacy, security, surveillance and human enhancement i.e. concerns have been raised about small "nanospy"- cameras and tracking devices as well as artificial organs and muscles developed via nanotechnology and nanomaterials.

- Equity of access, and impacts on national economies and industries i.e. nanotechnology $R \& D$ is highly resource intensive on the one hand as well as it being a technology that might give substantial competitive advantages to some members of society. This again can disrupt national economies and industries and maybe even societies at a pace not seen or experienced before. 
- Public involvement in technology development i.e. lack of public involvement in decisions about a substantial level of public funding being invested into nanotechnology $R \& D$ and decision about which areas of the technology should and should not be pursuit [24].

- The emergence of a global nanodivide i.e. nanotechnology $R \& D$ is highly resource intensive and hence not all economies have equal access to beneficial technologies and materials and hence concern has been raised that there will be a divide between the Global South and the Global North [25].

- Concerns about the risk of the development and convergence of nanotechnology, biology and computer technology i.e. development of a combination of technology, biological organisms with artificial intelligence. In the extreme case human cyborgs [26].

\section{Can the chemical risk assessment paradigm be applied to nanotechnology?}

In most countries existing regulation of nanomaterials is highly dependent on (eco)toxicological data and risk assessments to support and implement regulations. When risk assessment of nanomaterials is discussed, it is often narrowly portrayed as an extension of chemical risk assessment, consisting of four parts: hazard identification, dose-response assessment, exposure assessment, and risk characterization.

A number of studies have reported having completed risk assessments or modelled risk assessment for selected nanomaterials such as $\mathrm{CeO}_{2}$-based (cerium oxide) diesel fuel additive in the UK [27], and the use of nano-Ag (silver), nano- $\mathrm{TiO}_{2}$ (titanium dioxide) and CNTs (carbon nanotubes) in Switzerland [28]. For instance, Park et al. [27] concluded that "it is highly unlikely that exposure to cerium oxide at the environmental levels (from both monitored and modeled experimental data) would elicit pulmonary inflammation". Assuming worst-case exposure levels, Mueller and Nowack [28] find that the risk quotient ${ }^{3}$ for nano-Ag and CNT is less than a one thousandth, and they state that their modelling suggests that currently little or no risk is to be expected from nano-Ag and CNT to organisms in water and air. Nano-TiO2, on the other hand, might pose a risk to organism in water, with risk quotients ranging from $>0.7$ and $>16$. Risk quotients for soil could not be determined due to lack of information. Considering the results of the work done by Park et al. [27], and Muller and Nowack [28], it becomes clear that each element of risk assessment holds general as well as specific limitations and challenges.

In the context of chemical risk assessment, hazard identification can be defined as the "identification of the adverse effects which a substance has an inherent capacity to cause" [29]. But what if, as in the case of many nanomaterials any potential negative effects on human health and the environment are still speculative and unsubstantiated. It is still virtually impossible to systematically link reported nanoparticle properties to the observed effects for effective hazard identification [30].

The second element of chemical risk assessment (i.e. dose-response assessment) holds a number of limitations as well, when it comes to nanomaterials. Dose-response assessment involves: "...an estimation of the relationship between dose, or level of exposure to a substance, and the incidence and severity of an effect' [29]. The problem in the context of nanotechnology is that, while conventionally dose refers to 'dose by mass', early indications suggest that biological activity of nanoparticles might not be mass-dependent, but dependent on physical and chemical properties. The key problem for risk assessment is that currently physical and chemical properties are not routinely considered in toxicity studies [31]. Additionally it remains unclear whether a "no effect threshold' can be established, what the best hazard descriptor(s) of nanoparticles are and what the most relevant endpoints might be [30].

Consequently, Hansen et al. [32] proposed, that when estimating the hazard of nanomaterials, one needs to consider information that assists in describing a nanomaterial from a physical and

\footnotetext{
${ }^{3}$ Expected exposure concentration divided by to threshold concentration for harmful effects
} 
chemical perspective, i.e. chemical composition, size, shape, crystal structure, surface area, surface chemistry, surface charge, solubility, and adhesion ([33], [34] , [35], [36], [37], [38], [39], [40], [41],[42]). Unfortunately information on many of these properties is still largely unavailable for most nanoparticles tested. This lack of information in turn makes it difficult to identify the key characteristics - or combinations of key characteristics - that are responsible for hazards described in (eco)toxicological studies of these nanoparticles. Additionally it is conceivable that properties as yet not identified in the scientific literature may be of relevance for the hazard identification of some nanomaterials.

As the third element of chemical risk assessment, exposure assessment is another key element, as without exposure, there is no risk. Exposure assessment involves "...an estimation of the concentrations/doses to which human populations (i.e. workers, consumers and man exposed indirectly via the environment) or environmental compartments (aquatic environment, terrestrial environment and air) are or may be exposed" [29]. But the extensive knowledge (i.e. manufacturing conditions, level of production, industrial applications and uses, consumer products and behavior, and environmental fate and distribution) required to perform meaningful exposure assessment is as yet not available for most nanomaterials. Exposure assessment is further hindered by difficulties in monitoring nanomaterial exposure in the workplace and the environment, partly due to the fact that the biological and environmental pathways of nanomaterials are still largely unexplored [43] and unknown and partly due to the paucity of knowledge and lack of access to information which hampers realistic exposure assessments.

Furthermore, to fully assess the potential impact of a particular nanomaterial it is also necessary to have information on the entire lifecycle of nanomaterials e.g. precise levels of nanomaterial production levels and nanomaterial-based consumer products on the market, air and water emissions of nanomaterials, the uses of nanomaterials for wastewater treatment, amounts and types of nanomaterials discharged into landfills, waste storage, and waste treatment facilities, size of accidental releases of nanomaterials, and intentional uses of nanomaterials for environmental remediation and treatment [44].

Resnick and Tinkle [45] describe the risks inherent in nanomaterials to humans and animals through the concept of exposure route. They claim that due to the diversity of the nanomaterials no generalization about the safety of them can be made, and hence they have to be considered more or less individually. A key aspect of each particular nanomaterial is its physiochemical properties, size and shape. These properties in turn are dependent on the microenvironment that the material is situated in and these properties may change when a material enters an organism or the microenvironment changes in some other manner.

Risk characterization is the final part of chemical risk assessment where all information gathered during the first three steps of risk assessment comes together [43]. Often risk characterization boils down to the estimation of a risk quotient, typically defined as the ratio between the observed or derived no effect level and a predicted exposure concentration. If this risk quotient is $<1$ no further testing or risk reduction measures are needed, whereas further testing can be initiated to lower the risk quotient, if it is $>1$. If the risk quotient cannot be lowered readily below 1 , risk reduction could be implemented [29]. When it comes to nanomaterials, each of the first three elements of risk assessment holds limitations as noted above. Risk characterization being the final step in the procedure, may include the sum or perhaps even the product of the accumulated limitations as conveyed through the calculation of the risk quotients for nanoparticles.

Numerous high-level expert panels have reviewed the state-of-the-science on nanomaterial environmental, health and safety and there has been a considerable focus on identifying gaps of knowledge and provide recommendations on how to address and overcome these gaps [46]. Powell et al. [44] and Grieger et al. [46] identify a number of uncertainties surrounding nanomaterials, including, how to characterize nanomaterials and which parameters to measure, lack of toxicity/ecotoxicity data, limited data on of environmental fate and transport of nanomaterials and limited exposure data of human or environmental exposure data. This focus 
on lack of scientific knowledge, leads directly to the commonly expressed belief, that once we have the 'scientific facts' on toxicology and environmental impacts of nanomaterials 'objective' risk assessment will be possible and that this will then enables us to make informed decisions within a reasonable period of time, despite large uncertainties about the risks of nanotechnology and nanomaterials.

Brown [47] terms this the 'New Deficit Model' and asserts that it has as little validity as the original deficit model [81] that assigned the lack of knowledge to the general public. The New Deficit Model fails to acknowledge that the key issue for nanotechnologies is not lack of knowledge, but how to regulate in the face of fundamental uncertainties, including the reality that it will be arduous to calculate the toxicological data for many types of nanomaterials due the fact that often tens of different varieties of the one material are manufactured.

Additionally in the assessment of the environmental, health and safety risks of nanotechnology and nanomaterials privilege is usually given to scientific knowledge that can be measured, weighted and monitored. This ignores the importance of for instance metaphysical risks (see below) and the importance of values, ethics and tacit forms of knowledge [47] when judging risk. There are several inherent unavoidable value judgements in risk assessment and a separation of these from risk management tends to underemphasize these. Furthermore it overemphasize the role of technical experts and hence disenfranchises the general public, who ought to be involved and have a voice in risk assessment as well as determining risk management [48].

Shrader-Frechette argues that societal decision-making (i.e. risk management) involves legal rights, duties and ethical consequences that affect the welfare of persons, whereas purely scientific decision-making involves largely epistemological consequences [49]. Therefore the decision whether a society should accept any given technology should not be left to the risk assessors/scientists, but it should be left to the politicians who have the democratic mandate to make such decisions. This does of course not mean that politicians should be allowed to manipulate risk assessment to promote their own agenda, but it means that value-based decisions in the risk assessment process should be left to the political decision-makers.

\section{Expanding the conventional risk assessment paradigm}

It may well be necessary to look at risk and risk assessment for nanotechnology in a much wider sense. The implicit assumption of the conventional risk assessment paradigm is that uncertainties can be known or estimated. However this is not always the case and even when these uncertainties are known they are subject to a number of well-known biases and problems of unpredictability [50]. For instance, the outcomes of science-based/technical risk assessment are sensitive to the kinds of questions that are posed or not posed, how and by whom they are asked and the underlying assumptions that determine the questions [23]. Some of this is an inherent structural bias, in the sense that common material interests, social characteristics, and risk values are shared [51].

Unpredictability is especially pronounced in complex systems and a number of authors have argued ([23], [52]) that technological inventions like nanotechnology interfere with complex systems at a number of levels and hence may cause novel and unprecedented effects, that are virtually impossible to mitigate. Dupuy contends that at least for some complex nanoscale objects we will not be able to predict how they will behave, until we have created them [52]. As part of comprehensive risk management it is hence essential that early warnings are recorded and heeded, i.e. that procedures are in place to reverse decision to permit the production and sale of products that may cause in the long-term irreversible damage to humans or the environment.

To account for this unpredictability Wickson et al. [23] propose to use of the concept of incertitude when assessing nanotechnologies. The notion that modern risk assessment is or should be concerned with different kinds of uncertainty (collectively termed incertitude), was first proposed 
by Wynne in the context of scientific knowledge production and environmental policy [53]. This typology consists of:

- risk - the probability is calculable, knowledge is sufficient,

- uncertainty - probability as yet uncalculated, not enough knowledge yet,

- indeterminacy - knowledge is conditional and fallible,

- ambiguity - a number of different frames for calculation need to be used and

- ignorance - we are not aware of what we should calculate.

According to Wickson et al. [23] this typology enables us to see how risk assessment fails to take into account qualitative incertitude, and highlights scientific bias in terms of underlying worldviews, assumptions and interest. It does not however address risk from a moral philosophy point of view, nor does it give guidelines on how to perform the actual risk assessment (see below).

To address risk from a moral point of view, Hansson proposes to look at risk in terms of exemption i.e. it is a person's prima facie moral right not to be exposed to the risk of a negative impact through the actions of others. The question then is under what conditions can this inherent moral right be overridden. Or to restate the problem under what conditions is someone allowed to expose other persons to risk [50]? The rule that Hansson proposes is "nobody should be exposed to a risk unless it is part of an equitable social system for risk-taking that works to her advantage" [50]. Importantly this rule changes the agenda and agency of risk discussions; here each riskexposed person is treated as a sovereign individual, rather than an impersonal carrier of utilities and/or probabilities. Rather than proposing (as it is the case in conventional risk discussions), that it is acceptable to expose someone to a certain level of risk (considered 'safe'), using the rule above, sufficient reason, i.e. benefit, for accepting that an individual is exposed to risk must be provided.

\section{Alternatives to conventional risk assessment}

Regulators, industry and leading scientists within toxicology and economics have exhibited a tendency to discuss the risk of nanomaterials in the limited context of physical risks and chemical risk assessment and cost-benefit analysis. This approach is the accepted approach promulgated by science government and industry and believed to have been used successfully in the past (even though many examples exist to the contrary). Others actors, such as NGOs, the public and more progressive scholars consider nanorisk, as well as other risks (e.g. chemical, GM) through a more comprehensive lens and include societal issues such as "fairness", "voluntaribility", "familiaribility", "catastrophic potential", and "risk-benefit distribution among social groups" [54], [55].

To broaden conventional risk assessment and address some of these concerns a risk governance framework for nanotechnology has been suggested [56]. Essentially a risk governance framework is a policy response to risk in the broadest sense of the word. Its purpose is to expand conventional technical risk assessment and thereby to include broader concepts of risks. The concept of governance also shifts the responsibility from the state (that governs and its institutions involved in government) to a more diffuse collection of 'actors' or 'stakeholders' that all become involved in 'conventions, rules, processes and mechanisms concerned with how relevant risk information is collected, analyzed and communicated, and how management decisions are taken' [56]. It may also include contextual factors such as institutional arrangements and political values, including different perceptions of risk.

The International Risk Governance Council ${ }^{4}$ (IRGC) proposed a general Risk Governance Framework, which they also applied to nanotechnology [56]. On first appearance the framework is able to include not only assessment of physical harm, but broader issues of risk, including societal issue, stakeholder participation and uncertainties regarding knowledge. It attempts to

\footnotetext{
${ }^{4}$ See http://www.irgc.org/
} 
manage different types of risk and associated risk assessment procedures by introducing a temporal framework of four generations of nanotechnologies: passive nanostructures (from 2000), active nanostructures and nanodevices (from 2005), integrated nanosystems (after 2010) and heterogeneous molecular nanosystems (after 2015). Risk assessment for each generation is dependent the type of knowledge associated with this technology and the admission that technologies imagined or currently in the early prototype stage, but only commercially available in the more or less distant future, have decreasing available knowledge in the present.

Bijker et al. have criticized this temporal framework, arguing that the purpose and application of a technology, rather than the technology itself determine the risk, irrespective of when it will be introduced [57]. Public participation by stakeholders, while given a role in the value-based assessment of the ethical and social aspects of the new technology, is still perceived as a factual input, as part of an expert-driven process, rather than enabling empowerment of citizens and coresponsibility of governance [58].

In a broader sense the IRGC project and subsequent report on a conceptual risk governance of nanotechnology [59] also proposed a framework that attempted to integrate into the risk benefitanalysis environmental, health and safety, as well as ethical, legal and social issue. The overall risk assessment and management framework is cyclical, and appears open to the possibility of adaptation. However the risk appraisal stage is subdivided into risk assessment (i.e. in effect traditional risk 'scientific' assessment) and concern assessment (risk perception, social concern, social-economic impacts), and it might be tempting, even if not intended to fall into the trap of identifying the former as legitimate (ie. scientific), while the latter could be viewed as 'political, hence of a different sort of weight/legitimacy?

\section{Nanotechnology and metaphysical aspects of risk}

A problem with chemical risk assessment and risk management as well as the risk governance framework proposed by IRGC is that technological risk assessment seldom/never addresses what we term metaphysical risk (in general as well as in regard to nanotechnology specifically). This is the risk to society and individuals, implicitly referred to by some philosophers of nanotechnology, resulting from the inherent reconceptualizing of nature that the metaphysical project of nanotechnology implies. Dupuy defines a metaphysical project in general (following Popper and before him Meyerson) as "a set of presuppositions about the structure of the world which are neither testable nor falsifiable empirically, but which nonetheless play an essential role in the progress of science" [60].

What then is the metaphysical project of nanotechnology and what sort of risks may it produce? For Dupuy, the risk (and it is an existential risk to humanity) is captured in the notion of the rebellion of technoscience against the human condition. Technoscience here is science that is oriented towards fabrication of tools and devices, were transforming and knowing are intertwined rather than as in classical science were observing and understanding nature is the focus [61]. For Dupuy, the question is not if we should change and expand human characteristics (for instance in terms of developing/aspiring to human enhancements) and what that might mean for human concepts of ourselves, but what it means to be human in the sense of the human condition, that is what it means for us to be human and whether new technologies may change this. In harking back to Hannah Arendt, he defines the human condition as a mixture of things given (the environment/nature/our genes) and things made (by humans). This rebellion of technoscience against the human condition manifests itself in the dream of overcoming/abolishing death and creating everlasting life as espoused in numerous texts on converging technologies and nanotechnologies (both fiction and non-fiction). Dupuy further points out that this rebellion is not only against man's finiteness but also against the shame of having been born rather than made this "existential nausea of knowing that man is not the foundation of his own being" [60]. For Dupuy then the aim of the metaphysical project underlying nanotechnology is to turn man into the maker of nature, to revolt against and overcome the given. The metaphysical project then is to redefine nature and life as artifacts and then to make nature into an artifact, to make artificial nature [52]. 
Nordman observes similarly that the project of the technosciences, with nanotechnology taking a key role, is to use 'nature to go beyond nature'. The project of 'with nature beyond nature' in practice "neither reduces spirit and culture to matter and nature, nor does it celebrate the scandalous creations of hybrids or monsters. Instead, it simply dissolves the received categorical difference of science and technology, nature and culture... into the idiom of engineering [62]."

Dupuy suggests that in the context of the metaphysical project the key question from an ethical point of view is then not how to manage risk, but how to develop new concepts of prudence [52] and perhaps replace and/or enhance risk management with prudence. Prudence not so much in the sense of caution, but in the sense of applying the four value-rational questions as outlined by Flyvbjerg [63] and to be answered not in a technoscience, but a wider societal ability to respond to the questions of:

- Where are we going?

- Who gains and who loses, by which mechanisms of power?

- Is this development desirable?

- What should we do about it?

\section{Lay responses to (metaphysical) risk}

It is often asserted that predominantly psychological factors determine lay persons responses to risk. In particular, it is claimed that lay people's perception of risk is often influenced by factors such as whether their own exposure to the risk is involuntary or compromises societal values. These perceptions are typically not addressed in scientific risk assessment. There is also the commonly held belief amongst experts and governments that if people are given enough information to convince them that the benefits of a technology outweigh the risks and/or are included early enough in the deliberations about a technology they will find the technology acceptable and overcome earlier disquiet [64] - this is also known as the deficit paradigm [47].

First, it assumes that the experts know the true risk and as Shrader-Frechette argues, often they do not [65]. Second, it assumes that the perception of risk of laymen is wrong. Although they may lack some certain basic information, often their conceptualization of risk is much richer than that of the expert. It frequently includes other factors than just probability of fatalities, such as considerations about uncertainty, controllability, the benefits of taking a specific risk and threats to future generations ([65], [54], [66] [67], [68]). Due to heuristics and biases, experts may be as prone to overconfidence as lay persons, when they have to go beyond available data [54] and do not necessarily make more correct judgments about uncertainty than laymen do [69]. Third, when proponents of a given technology call for "public education", it seems to be public persuasion rather public information they are talking about. This is problematic because it does not only assume that the communicator knows what is true, but also that he knows what is good and right for society [68]. Instead, the public needs to be seen as a legitimate partner and be involved in both the risk assessment and the risk management process [70]. Past experiences have shown that the public can contribute substantially to a scientific decision-making process [71]. This is supported by the results of a 1979 survey conducted by the European Commission on consumer acceptance related to technological developments. The main lesson learned from the survey, was that the anxiety shown (by Europeans) about some consequences of scientific and technical development is neither undifferentiated nor blind to reasoning. This was especially true in relation to considerations of the risks that may sometimes be run by playing safe i.e. being precautious (Report by the Commission from 1979 cited in [72]).

Yearly [73] discusses how the objectivistic, universalizing claims of scientific experts used in risk assessment tend to overlook local contextual information and hence come to conclusions that stand in opposition to the experience of local people. It is this local knowledge that according to Wynne [53] is often non-certain and in the realm of ignorance or indeterminacy (as defined 
above). Wynne further argues that the public is often better equipped at deciding matters of ignorance and indeterminancy.

We additionally argue here that indeterminancy, ambiguity and ignorance are expressions of metaphysical risks and that somewhat surprisingly 'lay people' understand and express in their 'fears' the perception of metaphysical risks that they are being subjected to.

Laurent and Petit outlined already in 2005 the fears associated with emerging nanotechnologies. They presented these as a triangle with three corners: the fear of loss of control (the experiment goes wrong), the fear of abuse of the discoveries and the fear of transgression (attempting to overcome natural limits) [74]. A more recent EU sponsored project - DEEPEN, engaged a variety of lay persons across Europe and uncovered similar responses, which they grouped together into five key narratives, which partly map onto and overlap the above triangle: 1 . 'Be careful what you wish for' (desire); 2. 'Opening Pandora's box' (evil); 3. 'Messing with nature' (sacred); 4. 'Kept in the dark' (alienation); and 5. 'The rich get richer and the poor get poorer (exploitation)' [75]. The stories that lay people tell about nanotechnology clearly express perceptions about nanotechnology that go beyond conventional physical risks and focus on uncertainly of benefits associated with technoscience and a profound perception that nanotechnology has the potential to "re-shape our entire experience of living in the world [75]". The narrative 'opening Pandora's box' and 'messing with nature' clearly delineate the feeling of the public that while the promises of nanotechnologies are seductive, the hubris and the danger of proceeding without limits and disrupting long-standing boundaries is also very much present. Perhaps surprisingly to some the 'public' continues to resist the Enlightenment idea, so cherished by the technoscience establishment, that technological progress and social improvements are inextricably linked.

Clearly the public's responses are informed by historical experiences of technological, economic, and social developments and are embedded in deeply ingrained values about the world. But nanotechnologies introduce new and different ways of thinking about technology, new and different ambitions of what humans might be able to achieve. The concept of design takes the central role in nanotechnology, culminating in the "notion of the infinite plasticity and potentiality of all things [76]" - artifact, humans plants, animals, society.

Perhaps the public is expressing its disquiet about these new approaches and is perhaps instinctively wary of the metaphysical project that lies behind and at the root of nanotechnology. The DEEPEN project report alludes to this by suggesting that "in addition to an economic, scientific, or technological benefit/risk analysis, what is needed is therefore a philosophical hope/risk analysis. To the stories about public worries and concerns about nanotechnology one might now go beyond the DEEPEN project to add the stories of hope and of the ambivalence, even dangers of hope. By analyzing these stories, an expanded notion of 'risk' will come to the fore - a risk to self and community as hopes are disappointed or basic tenets betrayed"[76].

\section{A precautionary nanorisk appraisal framework: some thoughts}

\section{Combining principles and criteria in case of risk and uncertainty}

Stirling [80] suggests that the challenge in governing technology risk is both epistemic and ontological. Ontological issues require resilience and robustness, as technology and nature often (re)act in unpredicted ways. Epistemic risk, i.e. uncertain and contested knowledge of complex dynamics is best mitigated using precaution. Table 1 summarizes types of risk and potential assessment methods, including suggested policy/governance responses.

After reviewing the literature Grieger et al. [46] found that we are in the state of ignorance and indeterminacy when it comes to nanotechnology and nanomaterials and the questions is how to formulate an appropriate precautionary policy/governance response? Short of a fundamental cultural shift both within government and industry there are no easy answers. 
Additionally a key problem with current risk assessment approaches and governance frameworks has been their inability to incorporate flexibility and learning (differentiated and incremental) especially the inclusion of systematic institutional and procedural arrangements to facilitate listening for 'early warnings' (to recognize emerging risks) and a capability to (re) act to them. We suggest that the incorporation of such a capability will from a crucial basis to manage technological risk in general and nanotechnology risk in particular.

Table 1: (adapted from Stirling [79]) risks, types of knowledge and assessment options

\begin{tabular}{|l|l|l|l|l|}
\hline $\begin{array}{l}\text { Types } \\
\text { Uncertainty }\end{array}$ & $\begin{array}{l}\text { Knowledge } \\
\text { about } \\
\text { Outcomes }\end{array}$ & $\begin{array}{l}\text { Knowledge } \\
\text { about } \\
\text { Likelihoods }\end{array}$ & $\begin{array}{l}\text { Possible Assessment } \\
\text { Options }\end{array}$ & $\begin{array}{l}\text { Policy/ } \\
\text { Governance } \\
\text { Response }\end{array}$ \\
\hline Risk & $\mathbf{V}$ & $\begin{array}{l}\text { Risk/Cost-Benefit } \\
\text { analysis } \\
\text { Multi-criteria Assessment } \\
\text { Probabilistic Techniques }\end{array}$ & $\begin{array}{l}\text { Traditional } \\
\text { Risk } \\
\text { Assessment }\end{array}$ \\
\hline Ambiguity & $\mathbf{V}$ & $\mathbf{V}$ & $\begin{array}{l}\text { Participatory Deliberation } \\
\text { Scenarios/ Backcasting } \\
\text { MC mapping, Q-Method }\end{array}$ & Precautionary \\
\hline Uncertainty & $\mathbf{V}$ & $\begin{array}{l}\text { Uncertainty Heuristics } \\
\text { Interval Analysis } \\
\text { Sensitivity Analysis }\end{array}$ & Precautionary \\
\hline $\begin{array}{l}\text { Ignorance Indeterminacy } \\
\text { \& }\end{array}$ & $\mathbf{N}$ & $\mathbf{N}$ & $\begin{array}{l}\text { Monitor, } \\
\text { Research } \\
\text { Adaptive Management } \\
\text { Social/Institutional } \\
\text { Learning }\end{array}$ & Precautionary \\
\hline
\end{tabular}

Note: $\sqrt{ }=$ yes $X=$ no

Proposed fundamental risk assessment principles and criteria for nanotechnology

The essential first step in developing or in assessing a nanorisk governance framework is to clarify the basis for policy decisions and directions and to clearly outline how the concept of risk is framed. What are then the key conceptual elements or principles that should drive a nanorisk assessment and hence a nanorisk governance framework? In this regard a principle reflects a fundamental societal, institutional and/or ethical standpoint under which certain policy options are entirely ruled in or out. Fundamental principles, once agreed upon should be followed as a rule, and hence if a fundamental principle is violated, it is the technology that has to give, rather than the principle. In contrast policy options can also be evaluated in regard to various criteria (e.g. costs, impacts, benefits) which may be weighed against each other in the sense that loss in one areas might be compensated by a gain in another area.

From an ethical perspective, Lemons et al. [77] and Shrader-Frechette [66] have a number of arguments why ethical preferences should be given to minimizing the risk of harmful activities and technologies (i.e. overregulation) over the risk of potentially limiting the market penetration of a societal beneficial activity or technology (i.e. underregulation). First, it can be argued that it is more important to protect the public from harm than to provide for welfare in some positive sense because protection from harm seems to be a necessary condition for enjoying other freedoms. Second, the public typically needs more risk protection than do industry or government proponents of risky technology, partly because members of the public usually have fewer financial resources and have generally less information to respond to societal hazards that may affect them, and are additionally often faced with bureaucratic denials of public danger ([78], [66], [49]).Third laypersons ought to have guaranteed legal rights to protection against technological 
decisions that could threaten their health and physical security considering that everyone has both, due-process rights and rights to bodily security. And fourthly the failure to minimize harmful activities would result in using members of public as means to fulfil the needs of industry and society as a whole. This would be a discriminating practice, because these members of public would have to bear a significantly higher risk without consent despite the fact that others would receive most of the benefit ([66], [49]).

Given that nanotechnology is predicted to revolutionize 'everything', it is remarkable that its risk assessment has so far has been trapped in a conventional risk assessment paradigm. For nanotechnology to truly reach its potential it will be essential that its risk assessment is ethical, adaptive, precautionary and responsive to societal demands. The key principles associated with a precautionary approach to risk management can be summarized as follows (after [79]):

- $\quad$ 'Prevention' - a duty to prevent rather than to control.

- 'Polluter Pays' - the placing the burdens on all parties responsible for, or benefiting from, damaging activities.

- $\quad$ 'No Regrets' - favoring options that simultaneously satisfying economic, environmental and wider criteria and consider the availability of technical alternatives

- 'Clean Production' - adopt only those technologies which are demonstrably of lowest impact.

- Biocentric - recognizing the intrinsic value of non-human life and recognize the vulnerability of the natural environment.

- $\quad$ Limited knowledge - acknowledge the limitations of science, our knowledge and the possibility of surprise.

- $\quad$ Uphold the rights of those who are adversely affected by technologies.

In effect using a precautionary rather than a narrow risk appraisal framework, science and scientific research, will again be enable to fulfill their appropriate place in society: to provide information for policy, but not direct what is the best course of action for society. The latter is the appropriate task for society at large.

If we accept the nano risk universe as being capable of being described by the concepts of risk, uncertainty, indeterminacy, ambiguity and ignorance (as defined above), the essential second step in developing and assessing a nanorisk governance framework is to clarify the criteria on which risks are assessed and how this influences policy decisions and directions. "Criteria" are to be defined as factors that have to be considered when choosing between, or comparing, the pros and cons of different options, given that the fundamental principles, as outlined above are adhered to.

Both narrow risk and precautionary approaches (despite occasional claims to the contrary) are based in a 'scientific' appraisal of technology. What differentiate the two approaches are their view of knowledge and the role of wider societal considerations, when assessing risk. The currently prevalent narrow regime of risk appraisal applies a single perspective filter, has confidence in the knowledge used, places the proof of burden on skeptics, excludes alternatives, assumes claimed benefits and emphasis the rights of industry. This stands in contrast to a broad appraisal framework that allows for a plurality of filters, acknowledges different kinds of knowledge, places the proof of burden on the advocate of the technology, requires benefits to be justified and takes into account the rights of the wider society [79].

In conclusion to ensure the 'success' of nanotechnologies - products using nanomaterials and nanotechnologies for society we need a nano risk appraisal framework that adheres to the principles of precaution as outlined above and uses criteria for risk assessment that are transparent (open to inspection by all), adaptive (flexible and open to change/able to learn) and both incorporate qualitative and quantitative knowledge. 


\section{References}

[1] R.P. Feynman, There's plenty of room at the bottom - transcript of talk, 1959.

[2] N. Taniguchi, On the Basic Concept of 'Nano-Technology', Proceedings of the International Conference on Precision Engineering Part II, Japan Society of Precision Engineering, Tokyo, 1974.

[3] H.W. Kroto, J.R. Heath, S.C. O'Brien, R.F. Curl, R.E. Smalley, C60: Buckminsterfullerene, Nature (1985) 162-163.

[4] S. lijima, Helical microtubules of graphitic carbon, Nature Biotechnology (1991) 56-58.

[5] G. Binnig, H. Rohrer, C. Gerber, E. Weibel, Surface Studies by Scanning Tunnelling Microscopy, Physical Review Letters (1982) 57-61.

[6] A. McWilliams, Nanotechnology: A Realistic Market Assessment, BCC Research, 2010.

[7] M. Berger, Debunking the trillion dollar nanotechnology market size hype, Nanowerk, 2007.

[8] M.C. Roco, The emergence and policy implications of converging new technologies integrated from the nanoscale, Journal of Nanoparticle Research 7 (2005) 129-143.

[9] RS/RAE, Nanoscience and nanotechnologies: opportunities and uncertainties, Royal Society \& Royal Academy of Engineering, London, 2004.

[10] UK_Government, UK Nanotechnologies Strategy: small technologies, great opportunities, 2010.

[11] D. Fedrigo, R. Senjen, Shaping innovation: policy approaches on innovation governance the case of nanotechnology, Nanotechnologies in the 21st century, Brussels, 2010.

[12] ETC, The Big Down: Atomtech - Technologies Converging at the Nano-scale, 2003.

[13] J. Macoubrie, Informed Public Perceptions of Nanotechnology and Trust in Government, Woodrow Wilson International Centre for Scholars, Washington, 2005.

[14] Q. Chaudhry, J. Blackburn, P. Floyd, C. George, T. Nwaogu, A. Boxall, R. Aitken, Final Report: A scoping study to identify gaps in environmental regulation for the products and applications of nanotechnologies, Defra, London, 2006.

[15] K. Gavelin, R. Wilson, R. Donaldson, Democratic technologies? The final report of the Nanotechnology Engagement Group (NEG), Involve, London, 2007.

[16] M. Powell, New risk or old risk? How scientists' standpoints shape their nanotechnology risk frames, Health, Risk \& Society 9 (2007) 173-190.

[17] K. Kjølberg, G.C. Delgado-Ramos, F. Wickson , R. Strand T, Models of governance for converging technologies, Technology Analysis \& Strategic Management 20 (2008) 83-97.

[18] A. Mnyusiwalla, A.S. Daar, P.A. Singer, Mind the gap: science and ethics in nanotechnology, Nanotechnology (2003) 9-13.

[19] K. Kulinowski, Nanotechnology: from 'wow' to 'yuck.' Bulletin of Science, Technology, and Society (2004) 13-20.

[20] S. Wood, A. Geldart, R. Jones, Crystallizing the Nanotechnology Debate, Technology Analysis and Strategic Management 20 (2008) 13-27.

[21] R. Sandler, W.D. Kay, The GMO-Nanotech (dis)analogy, Bulletin of Science Technology and Society 26 (2006) 57-62.

[22] O. Renn, Concepts of risk: an interdisciplinary review - Part 1: disciplinary concepts, GAIA 17 (2008) 50-66.

[23] F. Wickson, F. Gillund, A.I. Myhr, Treating nanoparticles with precaution: recognising qualitative uncertainty in scientific risk assessment, in: K.L.a.F.W. Kjolberg (Ed.), Nano meets macro- social perspectives on nanoscale sciences and technologies, Pan Stanford Publishing, Singapore, 2010, pp. 445-472.

[24] Meridian Institute, Nanotechnology and the poor: opportunities and risks - closing the gaps within and between sectors of society, (2005).

[25] E. Court, A.S. Daar, E. Martin, T. Acharya, P.A. Singer, Will Prince Charles et al diminish the opportunities of developing countries in nanotechnology?, nanotechweb.org, 2004.

[26] ETC, The little big down: a small introduction to nano-scale technologies. available at: http://www.etcgroup.org/upload/publication/104/01/littlebigdown.pdf accessed 6th Oct 2010, 2004. 
[27] B. Park, K. Donaldson, R. Duffin, L. Tran, F. Kelly, I. Mudway, J.-P. Morin, R. Guest, P. Jenkinson, Z. Samaras, M. Giannouli, H. Kouridis, P. Martin, Hazard and Risk Assessment of a Nanoparticulate Cerium Oxide-Based Diesel Fuel Additive -A Case Study, Inhalation Toxicology 20 (2008) 547-566.

[28] N.C. Mueller, B. Nowack, Exposure modelling of engineered nanoparticles in the Environment, Environmental Science Technology 42 (2008) 4447-4453.

[29] European Commission JRC, Technical Guidance Document on Risk Assessment in support of Commission Directive 93/67/EEC on Risk Assessment for new notified substances Commission Regulation (EC) No 1488/94 on Risk Assessment for existing substances Directive 98/8/EC of the European Parliament and of the Council concerning the placing of biocidal products on the market Part I. EUR 20418 EN/1. European Communities, 2003.

[30] S.F. Hansen, Regulation and risk assessment of Nanomaterials - too little, too late?, Department of Environmental Engineering Technical University of Denmark, Lyngby, 2009.

[31] G. Oberdorster, E. Oberdorster, J. Oberdorster, Nanotoxicology: An emerging discipline evolving from studies of ultrafine particles, Environmental Health Perspectives (2005) 823839 .

[32] S.F. Hansen, B.H. Larsen, S.I. Olsen, A. Baun, Categorization framework to aid Hazard Identification of Nanomaterials, Nanotoxicology 1 (2007) 243-250.

[33] I. Beck-Speier, N. Dayal, E. Karg, K.L. Maier, C. Roth, A. Ziesenis, J. Heyder Agglomerates of ultrafine particles of elemental carbon and TiO2 induce generation of lipid mediators in alveolar macrophages, Environmental Health Perspectives (2001) 613-618.

[34] C.C. Berry, S. Wells, S. Charles, G. Aitchison, A.S.G. Curtis, Cell response to dextranderivatised iron oxide nanoparticles post internalisation, Biomaterials 25 (2004) 5405-5413.

[35] M.D. Cheng, Effects of nanophase materials $(<=20 \mathrm{~nm}$ ) on biological responses, J Environ Science Heal A 39 (2004) 2691-2705.

[36] P.R. Lockman, J.M. Koziara, R.J. Mumper, D.D. Allen, Nanoparticle surface charges alter blood-brain barrier integrity and permeability, J Drug Target (2004) 635-641.

[37] S.S. Nigavekar, L.Y. Sung, M. Llanes, A. El-Jawahri, T.S. Lawrence, C.W. Becker, L. Balogh, M.K. Khan, H-3 dendrimer nanoparticle organ/tumour distribution, Pharmaceutical Research (2004) 476-483.

[38] C.M. Sayes, J.D. Fortner, W. Guo, D. Lyon, A.M. Boyd, K.D. Ausman, Y.J. Tao, B. Sitharaman, L.J. Wilson, J.B. Hughes, J.L. West, V.L. Colvin, The differential cytotoxicity of water-soluble fullerenes, Nano Letters 4 (2004) 1881-1887.

[39] C. Baker, A. Pradhan, L. Pakstis, D.J. Pochan, S. S.I., Synthesis and antibacterial properties of silver nanoparticles. , Journal of Nanoscience Nanotechnology (2005) 244249.

[40] F.J. Martin, K. Melnik, T. West, J. Shapiro, M. Cohen, A.A. Boiarski, M. Ferrari, Acute toxicity of intravenously administered microfabricated silicon dioxide drug delivery particles in mice, Drugs Research Development (2005) 71-81.

[41] J.D. Fortner, D.Y. Lyon, C.M. Sayes, A.M. Boyd, J.C. Falkner, E.M. Hotze, L.B. Alemany, Y.J. Tao, W. Guo, K.D. Ausman, V.L. Colvin, J.B. Hughes, C-60 in water: Nanocrystal formation and microbial response, Environmental Science Technology 39 (2005) 43074316.

[42] T. Brunner, P. Piusmanser, P. Spohn, R. Grass, L. Limbach, A. Bruinink, W. Stark, In Vitro Cytotoxicity of Oxide Nanoparticles: Comparison to Asbestos, Silica, and the Effect of Particle Solubility, Environmental Science Technolology 40 (2006) 4374-4381.

[43] CCA, Small Is Different: A Science Perspective On The Regulatory Challenges of the Nanoscale. Ottawa: The Council of Canadian Academies, (2008).

[44] M.C. Powell, M.P.A. Griffin, S. Tai, Bottom-up risk regulation? How nanotechnology risk knowledge gaps challenge federal and state environmental agencies, Environmental Management (2008) 426-443.

[45] D.B. Resnik, S.S. Tinkle, Ethical issues in clinical trials involving nanomedicine, Contemporary clinical trials 28 (2007) 433-441. 
[46] K.D. Grieger, S.F. Hansen, A. Baun, The known unknowns of nanomaterials: Describing and characterizing uncertainty within environmental, health and safety risks, Nanotoxicology 3 (2009) 222-233.

[47] S. Brown, The new deficit model, Nature nanotechnology 4 (2009) 609-612.

[48] K.S. Shrader-Frechette, Practical Ecology and Foundations for Environmental Ethics, Journal of Philosophy 92 (1995) 621-635.

[49] K. S. Shrader-Frechette, Burying Uncertainty, University of California Press, London, 1993.

[50] S.O. Hansson, Philosophical Perspectives on Risk, Techné 8 (2004) 10 - 33.

[51] R. Sclove, Reinventing technology assessment - a 21st century model, Science and Technology Innovation Program, Woodrow Wilson International Centre for Scholars, Washington, DC 2010.

[52] J.-P. Dupuy, A. Grinbaum, Living with uncertainty: toward the ongoing normative assessemnt of nanotechnology, Techne 8 (2004) 4-25.

[53] B. Wynne, Uncertainty and environmental learning, Global Environmental Change 2 (1992) 112-127.

[54] P. Slovic, Facts versus fears: Understanding perceived risk., in: Kahneman D., Slovic P., Tversky A. (Eds.), Judgment under Uncertainty: Heuritics and Biases, Cambridge University Press, 1982, pp. 463-489.

[55] P. Slovic, Beyond numbers: A broader perspective on risk perception and risk communication., in: D.G. Mayo, R.D. Hollander (Eds.), Acceptable Evidence, Oxford University Press, 1991, pp. 48-65.

[56] O. Renn, White paper on risk governance: towards and integrative approach. White Paper No. 1. , International Risk Governance Council, Geneva, 2005.

[57] W.E. Bijker, I.D. de Beaufort, A. van den Berg, P.J.A. Borm, W.J.G. Oyen, G.T. Robillard, et al, A response to 'Nanotechnology and the need for risk governance' O. Renn \& M. C. Roco, 2006. J. Nanoparticle Research 8(2): 153-191, Journal of Nanoparticle Research 9 (2007) $1217-1220$.

[58] K. Kjølberg, G.C. Delgado-Ramos, F. Wickson , R. Strand, Models of governance for converging technologies, Technology Analysis \& Strategic Management 20 (2008) 83-97.

[59] O. Renn, M. Roco, White paper on nanotechnology risk governance No 2, International Risk Governance Council., Geneva, 2006.

[60] J.-P. Dupuy, Some pitfalls in the philosophical foundations of nanoethics, Journal of Medicine and Philosophy 32 (2007).

[61] A. Ferrari, Is it all about human nature? Ethical challenges of converging technologies beyond a polarized debate Innovation: The European Journal of Social Science Research $21(2008) 1-24$.

[62] A. Nordman, Enhancing material nature, in: K. Kjølberg, F. Wickson (Eds.), Nano meets macro - social perspectives on nanoscale sciences and technologies, Pan Stanford Publishing, Singapore, 2010, pp. 283-303.

[63] B. Flyvbjerg, Making social science matter: why social inquiry fails and how it can succeed again, Cambridge University Press, Cambridge, 2001.

[64] L. Frewer, A. Fisher, Nanotechnology in Foods: Understanding public response to its risks and benefits, in: K. Kjølberg, F. Wickson (Eds.), Nano meets marco - social perspectives on naoscale sciences and technology, Pan Stanford Pubblishing, Singapore, 2010, pp. 225-243.

[65] K.S. Shrader-Frechette, Scientific method, anti-foundationalism and public decision making, Risk (1990).

[66] K.S. Shrader-Frechette, Risk and Rationality, University of California Press Ltd., Berkeley, 1991.

[67] R.E. Kasperson, J.X. Kasperson, Hidden hazards in Acceptable Evidence in: D.G. Mayo, H. R.D. (Eds.), Acceptable Evidence: Science and Values in Risk Management, Oxford University Press, Oxford, 1991, pp. 9-28.

[68] H.P. Peters, Mass Media as an Information Channel and Public Arena, Risk Health Safety Environment (1994) 241-250. 
[69] D. Kahneman, A. Tversky, Subjective probability: a judgment of representativeness in: D. Kahneman, P. Slovic, A. Tversky (Eds.), Judgment under Uncertainty: Heuristics and Biases Cambridge University Press, Cambridge, 1982, pp. 32-47.

[70] V.T. Covello, P.M. Sandman, P. Slovic, Guidelines for communicating information about chemical risks effectively and responsibly, in: D.G. Mayo, H. R.D. (Eds.), Acceptable Evidence Oxford University Press, Oxford, 1991, pp. 66-90.

[71] J.A. Tickner, Children's environmental health: A case study in implementing the precautionary principle, International journal of Occupational and Environmental Health (2000) 281-288.

[72] S.A. Feenstra, Consumer acceptance of irradiated foods, in: S. Thorne (Ed.), Food Irradiation, Elsevier Applied Science, 1991, pp. 97-128.

[73] S. Yearley, Making systematic sense of public discontents with expert knowledge: two analytical approaches and a case study, Public Understanding of Science 9 (2000) 105122.

[74] L. Laurent, J.-C. Petit, Nanosciences and its convergence with other technologies- new golden age or apocalypse? Hyle 11 (2005) 45-76.

[75] S. Davies, P. Macnaghten, M. Kearnes, Reconfiguring Responsibility: Lessons for Public Policy (Part 1 of the report on Deepening Debate on Nanotechnology), Durham University, Durham 2009.

[76] A. Ferrari, A. Nordmann, Reconfiguring Responsibility: Lessons for Nanoethics (Part 2 of the report on Deepening Debate on Nanotechnology). , Durham University, Durham, 2009.

[77] J. Lemons, K.S. Shrader-Frechette, C. Cranor, The precautionary principle: Scientific uncertainty and type I and type II errors, Foundations of Science 2 (1997) 207-236.

[78] D. Ozonoff, L.I. Boden, 1987. Truth and consequences: Health agency responses to environmental health problems, Science, Technology and Human Values (1987) 70-77.

[79] A. Stirling, On science and precaution in the management of technological risk, European Commission - JRC Institute Prospective Technology, Brussels, 1999.

[80] A. Stirling, From Precaution to Robustness: in governance of technological vulnerability, The vulnerability of technological Cultures: new directions in research and governance (workshop), Maastricjt, Netherlands, 2008.

[81] M. Kearnes, Macnaghten P., Wilsdon, J. Governing at the Nanoscale. Demos, (2006); available at <http://www.demos.co.uk/ publications/governingatthenanoscale>.)

[82] SwissRe, Nanotechnology: small matter, many unknowns. (2004), Zurich available at: www.swissre.com

[83] Poland CA, Duffin R, Kinloch I, Maynard A, Wallace WA, Seaton A, et al: Carbon nanotubes introduced into the abdominal cavity of mice show asbestos-like pathogenicity in a pilot study. Nature Nanotechnolology 2008, 3:423-428.

[84] Donaldson, K, Murphy, FA. Duffin, R. Poland CA, Asbestos, carbon nanotubes and the pleural mesothelium: a review of the hypothesis regarding the role of long fibre retention in the parietal pleura, inflammation and mesothelioma. Particle and Fibre Toxicology, (2010), 7:5 available at: http://www.particleandfibretoxicology.com/content/7/1/5 